\title{
Evaluation of the participation of hyaluronic acid with platelet-rich plasma in the treatment of temporomandibular joint disorders
}

\author{
Ali Nizar Harba ${ }^{A-F}$, Munir Harfoush ${ }^{C, E, F}$ \\ Department of Oral and Maxillofacial Surgery, Faculty of Dentistry, Damascus University, Syria \\ A - research concept and design; $\mathrm{B}$ - collection and/or assembly of data; $\mathrm{C}$ - data analysis and interpretation; \\ $D$ - writing the article; $E$ - critical revision of the article; $F$ - final approval of the article
}

Address for correspondence

Ali Nizar Harba

E-mail:aliharba89@gmail.com

Funding sources

None declared

Conflict of interest

None declared

Received on July 6,2020

Reviewed on August 3, 2020

Accepted on September 10, 2020

Published online on March 31, 2021

Cite as

Harba AN, Harfoush M. Evaluation of the participation

of hyaluronic acid with platelet-rich plasma in the treatment

of temporomandibular joint disorders. Dent Med Probl.

2021;58(1):81-88. doi:10.17219/dmp/127446

DOI

$10.17219 / \mathrm{dmp} / 127446$

Copyright

○) 2021 by Wroclaw Medical University

This is an article distributed under the terms of the

Creative Commons Attribution 3.0 Unported License (CC BY 3.0)

(https://creativecommons.org/licenses/by/3.0/).

\begin{abstract}
Background. Temporomandibular joint disorders (TMDs) are widely researched diseases in medical literature. They are associated with many symptoms, such as pain, limited mouth opening and joint sounds, resulting in decreased quality of life for the patient. Both the hyaluronic acid (HA) injection and the plateletrich plasma (PRP) injection have a remarkable efficacy in the treatment of TMDs.

Objectives. This study aimed to evaluate the participation of HA with PRP in the treatment of TMDs.

Material and methods. The sample consisted of 24 patients with unilateral or bilateral TMDs. They were divided into 2 groups: HA+PRP was used in the test group (12 patients); and HA alone was used in the reference group (12 patients). The injection protocol for both groups was 4 times at 2 -week intervals. Pain at mastication, masticatory efficiency, joint sounds, maximum mouth opening (MMO), and functional limitation in the mandibular movement were evaluated at 2 weeks, 1 month, 3 months, and 6 months after the last injection. The outcome variables were the visual analog scale (VAS) evaluations. The Likert-type scale was used to evaluate the functional limitation in the mandibular movement.

Results. The mean age was 30.58 years in the reference group, and 23.92 years in the test group. There was alleviation of symptoms in both groups through the follow-up periods. There were significant differences between the groups regarding pain at mastication, masticatory efficiency, MMO, and functional limitation at the end of the follow-up period $(p<0.05)$.

Conclusions. The study results suggest that the HA and PRP injection provides greater improvement in patients with TMDs as compared to the HA injection alone; this may be due to taking advantage of the properties of both HA and PRP.
\end{abstract}

Key words: hyaluronic acid, platelet-rich plasma, temporomandibular joint disorders 


\section{Introduction}

Temporomandibular joint disorders (TMDs) are an important problem faced by oral and maxillofacial surgeons and patients; TMDs involve the articular capsule and the associated structures, and it may be the cause of orofacial pain. ${ }^{1}$

Pain complaints due to TMDs are the second most common with regard to the human body (about 33\% of musculoskeletal pain). Most people aged 20-40 years have at least 1 of the symptoms of TMDs. ${ }^{2,3}$

Temporomandibular joint disorders include disk displacements, with or without reduction, that may be associated with inflammatory changes, such as capsulitis and retrodiscitis, or with degenerative changes, such as temporomandibular joint (TMJ) osteoarthritis and osteoarthrosis. ${ }^{3}$ Common symptoms include pain, which is aggravated by the mandibular movement, joints sounds (clicking or crepitus), a decrease in masticatory efficiency, and functional limitation in the mandibular movement. ${ }^{4}$ Medical history, clinical examination and radiographic evaluation are essential methods of diagnosing TMDs. ${ }^{4}$ Treatment options for TMDs include self-management, physical therapy, pharmacological management, and TMJ surgery in some cases. ${ }^{5}$

The intra-articular injection of various substances, such as hyaluronic acid (HA) and platelet-rich plasma (PRP), is considered as one of the conservative procedures with high efficacy in the treatment of TMDs. ${ }^{6-11}$ The use of intra-articular injections of HA (viscosupplementation), which is a high-molecular-weight polysaccharide, provides the lubrication and protection of the joint cartilage. ${ }^{1,12-16}$ Sodium hyaluronate is the sodium salt of hyaluronic acid; it is a physiological component of the synovial fluid and it is responsible for the lubrication of TMJ. . $^{17,18}$

Many studies have indicated the significant efficacy of the HA injection in the treatment of TMDs. ${ }^{1,6-8,13,16,17}$ This is due to its special properties that are similar to those of the synovial fluid - viscosity as well as lubricating and damping capacity. ${ }^{2}$ Besides, HA performs mechanical (lubricating the articular elements and reducing their wear), biological (blocking different inflammatory mediators) and metabolic (providing the necessary components of the metabolic process for the articular disk and cartilage) functions. ${ }^{19-21}$

Platelet-rich plasma (PRP) is a concentrated autologous solution of platelets that is obtained by the centrifugation of a blood sample. It contains many growth factors (GFs), such as platelet-derived growth factor (PDGF), transforming growth factor (TGF), vascular endothelial growth factor (VEGF), epithelial growth factor (EGF), insulin-like growth factor-1 (IGF-1), basic fibroblast growth factor (bFGF), and 3 blood proteins (fibrin, fibronectin and vitronectin)..$^{22,23}$
In recent years, the clinical applications of PRP have been diversified with regard to several therapeutic and cosmetic fields. ${ }^{24-26}$ One of these uses refers to the treatment of joint disorders, including TMDs. Platelet-rich plasma has been shown to decrease signs and symptoms of TMDs, and significantly improve the joint function..$^{11,27,28}$

Hyaluronic acid injections bring immediate, but unsustainable results, unlike PRP injections with their gradual effects, increasing in the long term. ${ }^{28}$ Numerous research has lauded the participation of HA and PRP in treating knee problems, such as osteoarthritis and traumatic injuries, and has recorded that this treatment combination is better than injecting each of the substances alone. ${ }^{29-31}$

This study aimed to evaluate the efficacy of the application of HA with PRP in the treatment of TMDs.

\section{Material and methods}

\section{Study design and sample}

A prospective observational study was carried out with a 6-month follow-up period between December 2018 and February 2020 at the Department of Oral and Maxillofacial Surgery, Faculty of Dentistry, Damascus University, Syria. The sample included patients referred for the evaluation and management of TMDs. The ethics committee consent was obtained (EC ref. No. 4887, 28/11/2018), and all participants signed an informed consent agreement for inclusion in the study sample.

The sample was randomly divided into 2 groups: - group I (reference group): 12 patients who received 4 intra-articular injection sessions $-1 \mathrm{~mL}$ of $\mathrm{HA}$ per session with a 14-day interval between sessions;

- group II (test group): 12 patients treated with an injection of $0.5 \mathrm{~mL}$ of HA in combination with $0.5 \mathrm{~mL}$ of PRP into TMJ per session for 4 sessions with a 14-day interval between sessions.

A specific information form was filled in for each patient. The information from medical history, clinical evaluation (Fig. 1) and radiographic examination (Fig. 2) was recorded. The patients were evaluated with the Wilkes classification. ${ }^{32}$

The patients in both groups had a diagnosis of intermediate (III), late intermediate (IV) or late (V) stage. The inclusion criteria were as follows: patients suffering from unilateral or bilateral TMDs. The exclusion criteria were patients with systemic diseases (e.g., rheumatoid arthritis, psoriatic arthritis or juvenile arthritis), those receiving therapy with anticoagulants and those who had shown symptoms of hypersensitivity to the HA solution. 


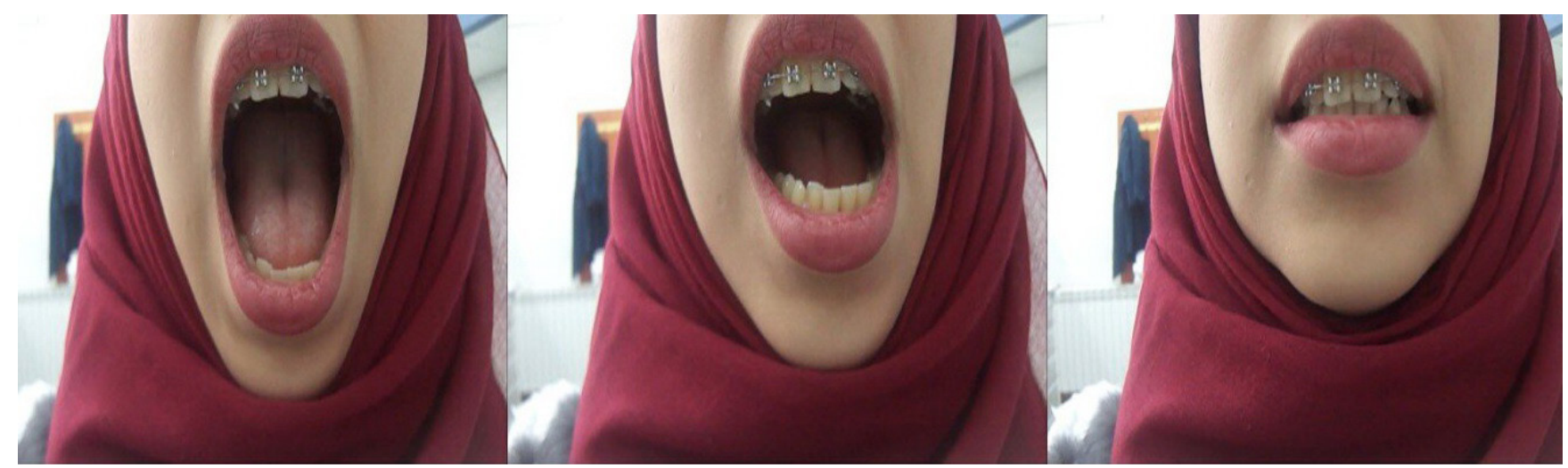

Fig. 1. Mandibular movements during clinical evaluation
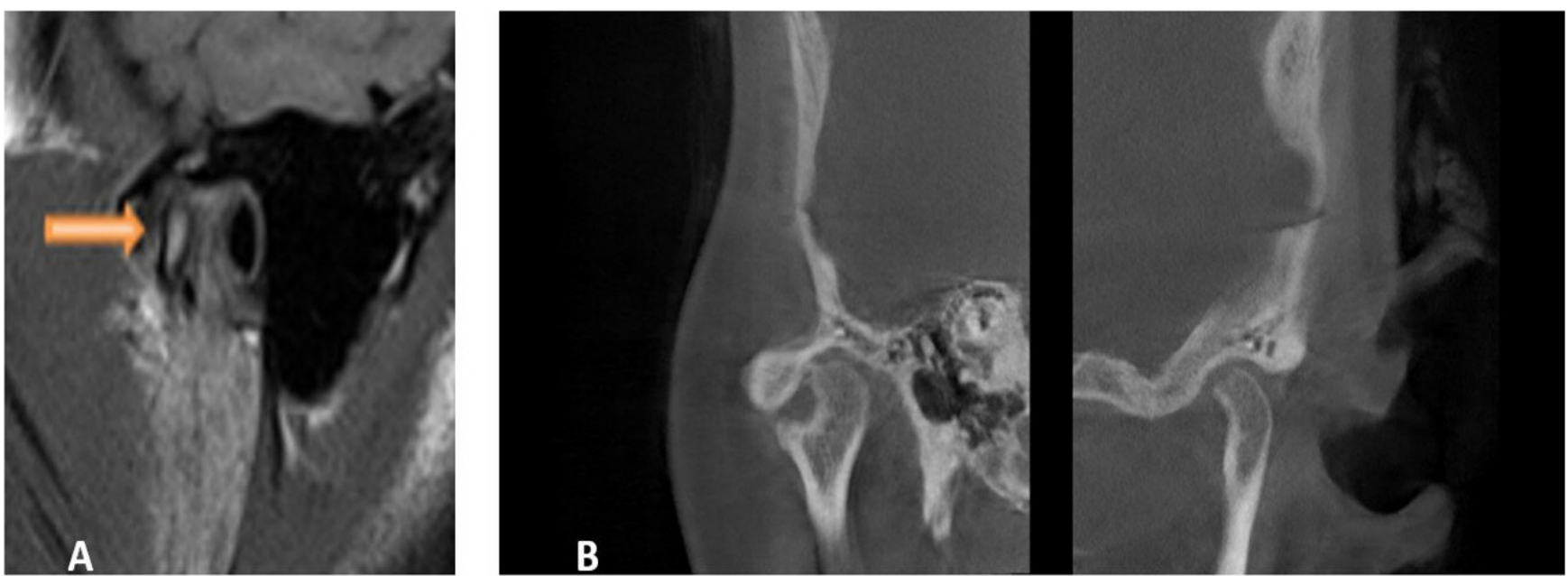

Fig. 2. Radiographic examination

A - anterior disk displacement (magnetic resonance imaging - MRI); B - temporomandibular joint (TMJ) osteoarthritis (cone-beam computed tomography - CBCT).

\section{Materials}

The following materials were used: 2-milliliter syringes of HA (Hyalgan ${ }^{\circledR}$; Fidia Farmaceutici, Abano Terme, Italy), different sizes of syringes, laboratory tubes containing sodium citrate, dry tubes, a centrifuge, a camera (Sony DSC-W710/B 16 MP; Sony, Tokyo, Japan), and a caliper.

\section{Treatment protocol and injection technique}

\section{Group I (HA alone):}

After receiving the patient, recording medical history, filling in the patient's form, and completing the diagnostic procedures (clinical, simple radiography, computed tomography (CT) and magnetic resonance imaging (MRI)), the patient was prepared for the $1^{\text {st }}$ injection session, which was conducted as follows:

- an allergy test for HA was performed;

- the lateral canthus-tragus reference points were used (Fig. 3) ${ }^{33}$; the entry point was $10 \mathrm{~mm}$ away from the middle of the tragus and $2 \mathrm{~mm}$ below the line, the mandibular condyle was forced into the anterior position, with the index finger remaining on the condyle as a safety guide;
- the skin surface was disinfected with povidone-iodine;

$-1 \mathrm{~mL}$ of HA was injected into the upper joint space with a 19-gauge needle; after removing the needle, the patient was asked to close their mouth slowly;

- special instructions were given after injection.

The injection was repeated 4 times, with 14-day intervals between sessions.

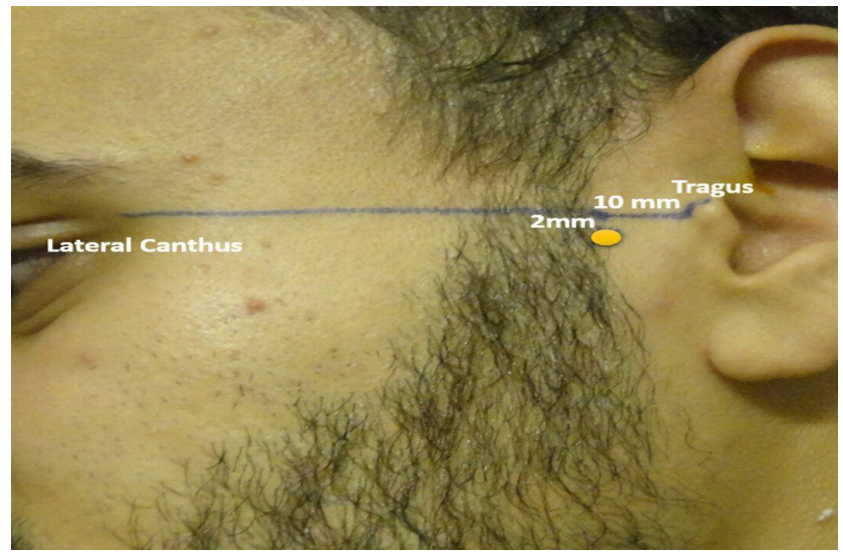

Fig. 3. Technique used for injections into the temporomandibular joint (TMJ) 


\section{Group II (HA+PRP):}

The patient was informed not to take antibiotics for a week before and after the injection because of their negative effects on PRP.

\section{Preparation of platelet-rich plasma}

The Marx protocol was adopted based on the study by Sabarish et al., ${ }^{34}$ which was preceded by two-step centrifugation procedures. Firstly, under strictly sterile conditions, $10 \mathrm{~mL}$ of peripheral blood was collected from the ulnar vein of the patient with a single-use syringe. It was placed in a tube containing sodium citrate as an anticoagulant (1/9), and then it was centrifuged for $4 \mathrm{~min}$ at a speed of $1,000 \mathrm{rpm}$. In the $2^{\text {nd }}$ step, PRP was separated from platelet-poor plasma (PPP) in a dry tube through centrifugation for $9 \mathrm{~min}$ at $800 \mathrm{rpm}$.

As in group I, we followed the same procedure before injection.

Then, $0.5 \mathrm{~mL}$ of HA was injected into the upper joint space, which was immediately followed by an injection of $0.5 \mathrm{~mL}$ of PRP.

The patient was asked to close their mouth slowly.

The injection was repeated 4 times, with 14-day intervals between sessions.

In an attempt to achieve a single-blind design, we did not inform the patient which of the treatment protocols they received.

\section{Outcome variables}

Pain at mastication was assessed using the visual analog scale (VAS) from 0 to 10; 0 meant 'no pain' and 10 - 'the worst pain the patient has ever experienced'.

Mastication efficiency was assessed with VAS from 0 to 10 , the extremes of which were 'eating only semi-liquids' and 'eating solid, hard food', respectively.

Joint sounds: the scale was anchored with 'no noise' (score 0 ) and 'noise as excessive as it could be' (score 10).

Maximum mouth opening was measured in millimeters.

Functional limitation in the mandibular movement was assessed with the Likert-type scale ( 0 - absent; 1 - slight; 2 - moderate; 3 - intense; and 4 - severe).

All outcome variables were evaluated at 2 weeks, 1 month, 3 months, and 6 months after the last injection.

\section{Statistical analysis}

The results were analyzed with the IBM SPSS Statistics for Windows software, v. 24.0 (IBM Corp., Armonk, USA), The Wilcoxon and Mann-Whitney $U$ tests were used for intragroup and intergroup comparisons, respectively. Significance was set at a $p$-value less than 0.05 for all statistical tests.

To achieve a statistical study and to check changes within each group, the arithmetic means of each variable were analyzed separately during the follow-up points in both groups, and finally we verified differences between the 2 groups before the treatment and after a 6-month follow-up.

Table 1. Intragroup comparisons of the outcome variables over time

\begin{tabular}{|c|c|c|c|c|c|c|c|c|c|c|}
\hline Variable & Groups & $\begin{array}{l}\text { Before } \\
\text { treatment }\end{array}$ & $p$-value & 2 weeks & $p$-value & 1 month & $p$-value & 3 months & $p$-value & 6 months \\
\hline \multirow{2}{*}{$\begin{array}{l}\text { Pain } \\
\text { at mastication } \\
\text { [VAS] }\end{array}$} & $\mathrm{HA}$ & $\begin{array}{r}6.500 \\
\pm 1.648\end{array}$ & $0.002^{*}$ & $\begin{array}{r}4.479 \\
\pm 1.568\end{array}$ & $0.002^{*}$ & $\begin{array}{r}3.313 \\
\pm 1.716\end{array}$ & 0.118 & $\begin{array}{r}2.750 \\
\pm 1.215\end{array}$ & $0.026^{*}$ & $\begin{array}{r}3.500 \\
\pm 1.348\end{array}$ \\
\hline & $\mathrm{HA}+\mathrm{PRP}$ & $\begin{array}{r}6.750 \\
\pm 2.463\end{array}$ & $0.002^{*}$ & $\begin{array}{r}3.250 \\
\pm 2.017\end{array}$ & $0.037^{*}$ & $\begin{array}{r}2.583 \\
\pm 1.881\end{array}$ & 0.363 & $\begin{array}{r}2.375 \\
\pm 2.090\end{array}$ & 0.618 & $\begin{array}{r}2.250 \\
\pm 2.105\end{array}$ \\
\hline \multirow{2}{*}{$\begin{array}{l}\text { Mastication } \\
\text { efficiency } \\
\text { [VAS] }\end{array}$} & $\mathrm{HA}$ & $\begin{array}{r}4.708 \\
\pm 1.824\end{array}$ & $0.002^{*}$ & $\begin{array}{r}6.417 \\
\pm 1.276\end{array}$ & $0.003^{*}$ & $\begin{array}{r}7.458 \\
\pm 1.389\end{array}$ & 0.305 & $\begin{array}{r}7.750 \\
\pm 1.055\end{array}$ & $0.040^{*}$ & $\begin{array}{r}7.333 \\
\pm 1.094\end{array}$ \\
\hline & $\mathrm{HA}+\mathrm{PRP}$ & $\begin{array}{r}3.833 \\
\pm 2.188\end{array}$ & $0.002^{*}$ & $\begin{array}{r}7.229 \\
\pm 1.042\end{array}$ & $0.023^{*}$ & $\begin{array}{r}7.708 \\
\pm 1.033\end{array}$ & 0.234 & $\begin{array}{r}7.875 \\
\pm 1.264\end{array}$ & 0.129 & $\begin{array}{r}7.897 \\
\pm 1.435\end{array}$ \\
\hline \multirow{2}{*}{$\begin{array}{l}\text { Joint sounds } \\
\text { [VAS] }\end{array}$} & $\mathrm{HA}$ & $\begin{array}{r}5.896 \\
\pm 1.704\end{array}$ & $0.002^{*}$ & $\begin{array}{r}3.729 \\
\pm 0.997\end{array}$ & $0.004^{*}$ & $\begin{array}{r}2.875 \\
\pm 0.856\end{array}$ & 0.719 & $\begin{array}{r}3.000 \\
\pm 1.022\end{array}$ & $0.012^{*}$ & $\begin{array}{r}3.958 \\
\pm 0.964\end{array}$ \\
\hline & $\mathrm{HA}+\mathrm{PRP}$ & $\begin{array}{r}6.917 \\
\pm 2.076\end{array}$ & $0.003^{*}$ & $\begin{array}{r}4.333 \\
\pm 1.600\end{array}$ & $0.003^{*}$ & $\begin{array}{r}3.042 \\
\pm 1.437\end{array}$ & 0.394 & $\begin{array}{r}2.833 \\
\pm 2.004\end{array}$ & 0.340 & $\begin{array}{r}2.667 \\
\pm 1.958\end{array}$ \\
\hline \multirow{2}{*}{$\begin{array}{l}\mathrm{MMO} \\
{[\mathrm{mm}]}\end{array}$} & $\mathrm{HA}$ & $\begin{array}{r}35.083 \\
\pm 10.544\end{array}$ & $0.003^{*}$ & $\begin{array}{r}40.875 \\
\pm 7.139\end{array}$ & 0.141 & $\begin{array}{r}41.750 \\
\pm 6.088\end{array}$ & $0.011^{*}$ & $\begin{array}{r}39.667 \\
\pm 5.047\end{array}$ & 0.506 & $\begin{array}{l}39.083 \\
\pm 6.313\end{array}$ \\
\hline & $\mathrm{HA}+\mathrm{PRP}$ & $\begin{array}{r}34.708 \\
\pm 9.418\end{array}$ & $0.004^{*}$ & $\begin{array}{r}43.583 \\
\pm 5.518\end{array}$ & 0.893 & $\begin{array}{r}43.917 \\
\pm 6.775\end{array}$ & 0.178 & $\begin{array}{r}43.042 \\
\pm 7.257\end{array}$ & 0.843 & $\begin{array}{r}42.875 \\
\pm 7.155\end{array}$ \\
\hline \multirow{2}{*}{$\begin{array}{l}\text { Functional } \\
\text { limitation } \\
\text { [Likert-type scale] }\end{array}$} & $\mathrm{HA}$ & $\begin{array}{r}2.042 \\
\pm 0.964\end{array}$ & $0.007^{*}$ & $\begin{array}{r}0.875 \\
\pm 0.433\end{array}$ & $0.025^{*}$ & $\begin{array}{r}0.458 \\
\pm 0.498\end{array}$ & 0.084 & $\begin{array}{r}0.708 \\
\pm 0.620\end{array}$ & $0.014^{*}$ & $\begin{array}{r}1.083 \\
\pm 0.515\end{array}$ \\
\hline & $\mathrm{HA}+\mathrm{PRP}$ & $\begin{array}{r}2.458 \\
\pm 0.891\end{array}$ & $0.003^{*}$ & $\begin{array}{r}0.875 \\
\pm 0.644\end{array}$ & $0.015^{*}$ & $\begin{array}{r}0.458 \\
\pm 0.582\end{array}$ & 0.257 & $\begin{array}{r}0.333 \\
\pm 0.492\end{array}$ & 0.180 & $\begin{array}{r}0.458 \\
\pm 0.542\end{array}$ \\
\hline
\end{tabular}

Groups: HA - hyaluronic acid alone; HA+PRP - hyaluronic acid with platelet-rich plasma; VAS - visual analog scale; MMO - maximum mouth opening; 


\section{Results}

The study sample consisted of 24 patients suffering from unilateral or bilateral TMDs; the sample was divided into 2 groups (HA group and HA+PRP group) with a mean age of 30.58 and 23.92 years, respectively.

The search variables were studied within each group over time by comparing them at each follow-up point with their predecessors, and in general, the results showed significant improvement in the 2 groups in all the variables (Table 1). The particular results were as follows:

\section{Pain at mastication}

In both groups, the pain decreased significantly through all follow-up points as compared to the pretreatment score, with statistically significant differences between the periods before treatment-after 2 weeks and 2 weeks -1 month $(p<0.05)$. In the HA group, the pain returned to increase with a statistically significant difference between the periods 6 months -3 months, in contrast to the $\mathrm{HA}+\mathrm{PRP}$ group, where it continued to decline until the end of the follow-up (Fig. 4).

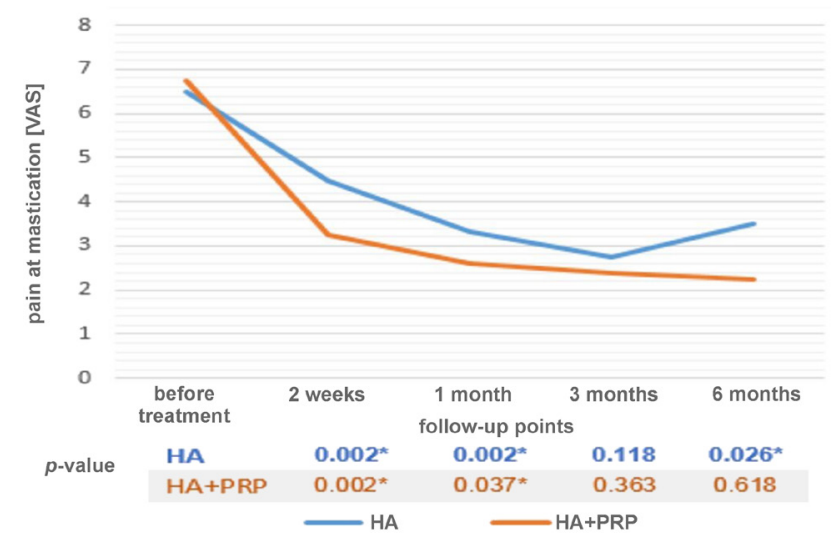

Fig. 4. Pain at mastication at the time of the study

* statistically significant.

\section{Mastication efficiency}

For this variable, an increase was expected; differences between the means were statistically significant when comparing the periods before treatmentafter 2 weeks and 2 weeks -1 month $(p<0.05)$ in both groups.

The mastication efficiency increase in the HA+PRP group continued until the end of the follow-up, while it decreased in the HA group, with a statistically significant difference from the previous period (Fig. 5).

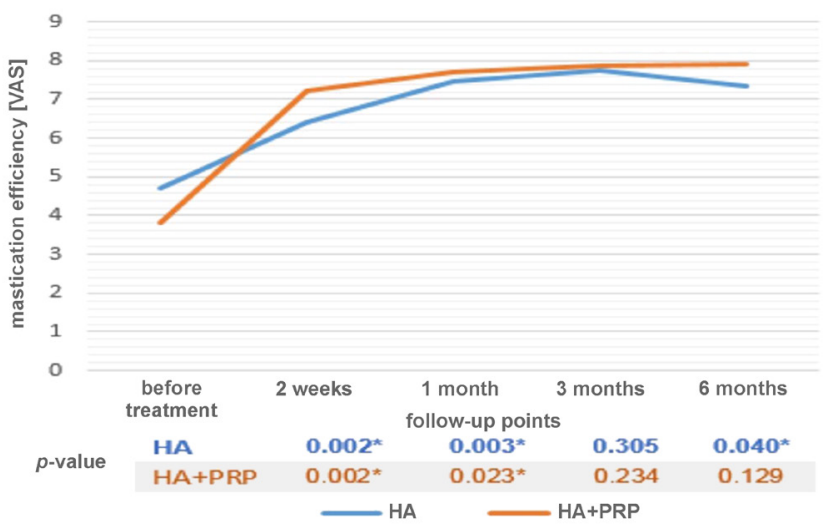

Fig. 5. Masticatory efficiency at the time of the study * statistically significant.

\section{Joint sounds}

Similarly to what happened in the case of the pain variable, a decrease was observed in the first follow-up periods, the scores in the HA group increased significantly at 6 months, while in the HA+PRP group, they continued to decrease (Fig. 6).

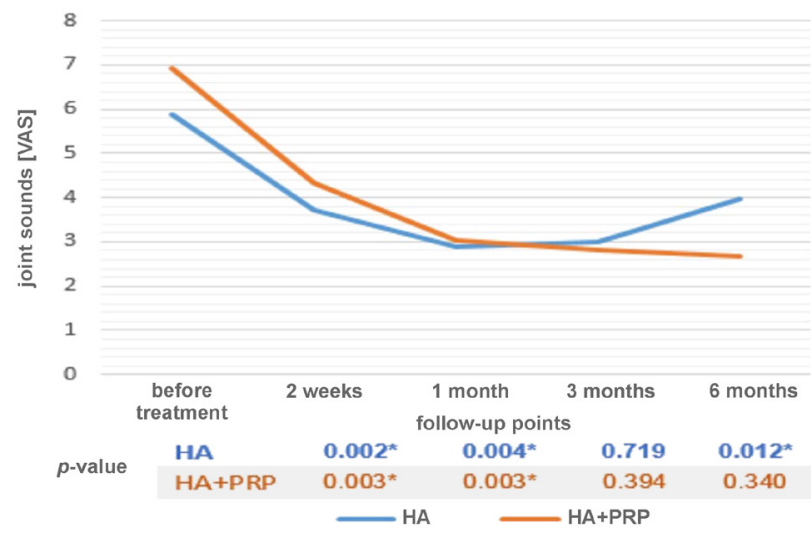

Fig. 6. Joint sounds at the time of the study

* statistically significant.

\section{Maximum mouth opening}

Measured in millimeters, there was an increase in the MMO values when comparing the periods before treatment-after 2 weeks with statistically significant differences. In the HA group, the mean MMO decreased when comparing the periods 3 months -1 month, also with a statistically significant difference. This did not happen in the HA+PRP group, where the mean MMO decreased slightly by about 0.16 at the end of the follow-up (Fig. 7). 


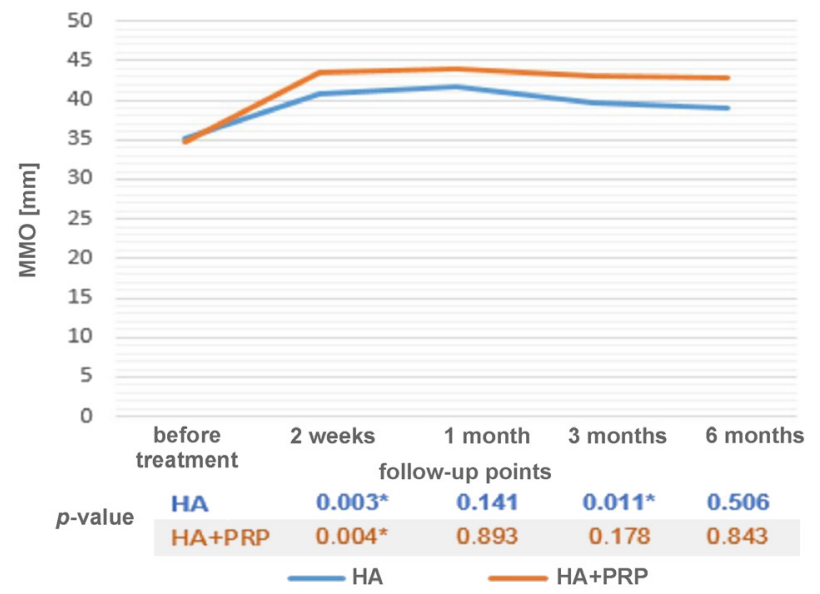

Fig. 7. Maximum mouth opening (MMO) at the time of the study * statistically significant.

\section{Functional limitation in the mandibular movement}

As other study variables, functional limitation decreased with statistically significant differences in the first followup periods, but again increased at the end (at 6 months) in both groups. Still, the HA+PRP group recorded a slight increase, unlike the HA group, for which $p<0.05$ (Fig. 8).

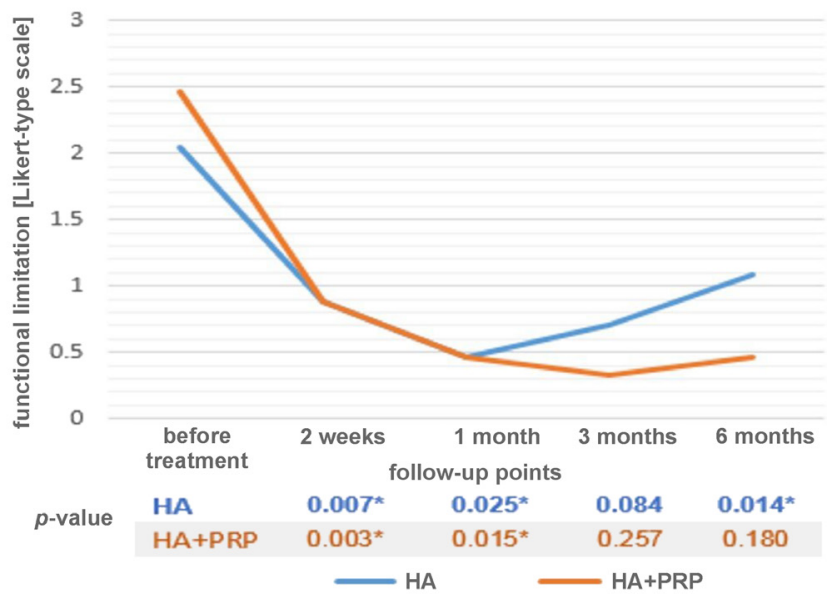

Fig. 8. Functional limitation of the mandibular movement at the time of the study

* statistically significant.

\section{Intergroup comparison}

Before treatment, it was noted that the means of some variables (pain, joint sounds and functional limitation) were higher in the HA+PRP group than in the HA group; they were lower at the end of the follow-up.

On the other hand, for other variables (mastication efficiency and MMO), the scores before treatment were lower in the HA+PRP group and became higher after 6 months.
The value of the significance level for all the variables of the 2 groups (HA and HA+PRP) in the pre-treatment period was greater than 0.5 . There were statistically significant differences in all variables at the end of the follow-up except for the variable of joint sounds, which was similar in both groups (Table 2).

Table 2. Intergroup comparisons of the outcome variables (before treatment and after 6 months)

\begin{tabular}{|l|c|c|c|c|}
\multirow{2}{*}{\multicolumn{1}{c|}{ Variable }} & \multicolumn{2}{c|}{ Before treatment } & \multicolumn{2}{c|}{ After 6 months } \\
\cline { 2 - 5 } & $Z$ & $p$-value & $Z$ & $p$-value \\
\hline Pain at mastication & -0.465 & 0.671 & -1.655 & $0.010^{*}$ \\
Mastication efficiency & -1.072 & 0.291 & -1.106 & $0.029^{*}$ \\
Joint sounds & -1.399 & 0.178 & -1.600 & 0.114 \\
MMO & -0.144 & 0.887 & -1.565 & $0.012^{*}$ \\
Functional limitation & -1.194 & 0.266 & -2.502 & $0.014^{*}$ \\
\hline
\end{tabular}

* statistically significant.

\section{Discussion}

The evaluation of the treatment of TMDs focuses on 2 important areas: pain relief and restoring the mandibular function without limitation, which results in improvement in mastication efficiency. ${ }^{3}$

The intra-articular injection of HA provides many therapeutic benefits in the treatment of TMDs and serves as a minimally invasive procedure. ${ }^{6}$ There is no need for surgical incisions and tissue dissection with this procedure, which decreases postoperative complications, such as facial nerve injuries, infection and severe pain. ${ }^{1,14}$

The use of PRP is also very beneficial, bringing significant and long-term improvement. ${ }^{28}$

The aim of the present study was to answer the question of whether the application of HA with PRP is superior to the HA injection alone in the treatment of TMDs. We started from the principle that HA has been commonly in use for the last 2 decades and has shown good efficacy; in addition to that, many authors have indicated improvement in the mandibular function without side effects associated to its use in treating TMDs. ${ }^{1,7,8}$ Therefore, we designed our study so that the reference group were the patients who received HA alone.

The findings of our study suggest that HA was effective in alleviating the symptoms in all of the follow-up periods. However, in the long-term, at the 6-month follow-up point, HA+PRP provided better results.

The mean pain score decreased significantly in the HA group in all follow-up periods as compared to the pretreatment period. It was 6.5 before treatment, 2.75 after 3 months and 3.5 at the end of follow-up, i.e., a significant decrease occurred. The HA+PRP group exhibited better performance as compared with the HA group, with the mean scores being $6.75,3.25,2.583,2.375$, and 2.250 , consecutively in the follow-up periods. 
Similarly to the previous variable, we found that the HA+PRP group had better mastication efficiency outcomes; the mean score at 6 months was 7.897 and 3.833 before treatment $(p=0.002)$, with a significant increase occurring in this group. In the HA group, an increase was achieved to a lesser extent and a decrease at the end of follow-up gave preference to the HA+PRP injection.

Although there were no statistically significant differences between the 2 groups concerning the joint sounds variable, the mean score in the HA group was 3 at 3 months and 3.958 at 6 months, i.e., an increase occurred, unlike in the HA+PRP group, where improvement continued until the end of follow-up.

The expected improvement was achieved in the variables MMO and functional limitation in both groups; however, preference was evident in the $\mathrm{HA}+\mathrm{PRP}$ group.

At present, the published data about PRP and HA combined in the treatment of TMDs with which we could compare our findings and interpretations are limited.

We can discuss our study with regard to what researchers have stated about the use of HA alone or PRP alone. In their study, Gencer et al. reported that an injection of HA was superior to tenoxicam and betamethasone in relieving TMD complaints, including pain, which was reflected in an increase in mastication efficacy. ${ }^{1}$ Kopp et al. reported similar findings associated with the clinical symptoms and dysfunction presented by patients. ${ }^{15}$ They found that HA was safer and more suitable with regard to the risk of the progression of joint degeneration in comparison with corticosteroids. ${ }^{15}$ On the other hand, PRP is an autologous solution; therefore, this method of treatment appears safe, especially that in recent years, this mixture (HA+PRP) has been studied in relation to the disorders of other body joints, such as the knee joint. ${ }^{30}$

\section{Conclusions}

The study findings suggest that the HA and PRP injection provides greater improvement in patients with TMDs as compared to the HA injection alone. This treatment method is safe enough as well as comfortable, and improves the quality of life of patients with TMDs.

\section{ORCID iDs}

Ali Nizar Harba (D) https://orcid.org/0000-0002-2419-7368 Munir Harfoush (D) https://orcid.org/0000-0002-3289-9191

\section{References}

1. Gencer ZK, Özkiriş M, Okur A, Korkmaz M, Saydam L. A comparative study on the impact of intra-articular injections of hyaluronic acid, tenoxicam and betametazon on the relief of temporomandibular joint disorder complaints. J Craniomaxillofac Surg. 2014;42(7):1117-1121. doi:10.1016/j.jcms.2014.01.041

2. De Leeuw R, Klasser GD, eds. Orofacial Pain. Guidelines for Assessment, Diagnosis, and Management. $4^{\text {th }}$ ed. Chicago, USA: Quintessence Publishing; 2008:1-20.
3. Okeson JP. Management of Temporomandibular Disorders and Occlusion. $8^{\text {th }}$ ed. eBook. Maryland Heights, USA: Mosby - Elsevier Health Sciences; 2019:101-254.

4. Bell WE. Temporomandibular Disorders. Classification, Diagnosis, Management. $3^{\text {rd }}$ ed. Chicago, USA: Year Book Medical Publishers; 1990.

5. Manfredini D. Fundamentals of TMD management. In: Manfredini D, ed. Current Concepts on Temporomandibular Disorders. Berlin, Germany: Quintessence Publishing; 2010:305-318.

6. Aktas I, Yalcin S, Sencer S. Prognostic indicators of the outcome of arthrocentesis with and without sodium hyaluronate injection for the treatment of disc displacement without reduction: A magnetic resonance imaging study. Int J Oral Maxillofac Surg. 2010;39(11):1080-1085. doi:10.1016/j.ijom.2010.07.001

7. Guarda-Nardini L, Rossi A, Arboretti R, Bonnini S, Stellini E, Manfredini D. Single- or multiple-session viscosupplementation protocols for temporomandibular joint degenerative disorders: A randomized clinical trial. J Oral Rehabil. 2015;42(7):521-528. doi:10.1111/joor.12282

8. Yeung RWK, Chow RLK, Samman N, Chiu K. Short-term therapeutic outcome of intra-articular high molecular weight hyaluronic acid injection for nonreducing disc displacement of the temporomandibular joint. Oral Surg Oral Med Oral Pathol Oral Radiol Endod. 2006;102(4):453-461. doi: 10.1016/j.tripleo.2005.09.018

9. Pihut M, Szuta M, Ferendiuk E, Zeńczak-Więckiewicz D. Evaluation of pain regression in patients with temporomandibular dysfunction treated by intra-articular platelet-rich plasma injections: A preliminary report. Biomed Res Int. 2014;2014:132369. doi:10.1155/2014/132369

10. Şimşek ME. Bilateral platelet rich plasma injections with assisted techniques for temporomandibular joint disorders. Eur Res J. 2016;2(1):42-45. doi:10.18621/eurj.2016.2.1.42

11. Kütük N, Baş B, Soylu $E$, et al. Effect of platelet-rich plasma on fibrocartilage, cartilage, and bone repair in temporomandibular joint. J Oral Maxillofac Surg. 2014;72(2):277-284. doi:10.1016/j. joms.2013.09.011

12. Emes $Y$, Arpınar IŞ, Öncü B, et al. The next step in the treatment of persistent temporomandibular joint pain following arthrocentesis: A retrospective study of 18 cases. J Craniomaxillofac Surg. 2014;42(5):e65-e69. doi:10.1016/j.jcms.2013.06.010

13. Tang $Y L$, Zhu GQ, Hu L, et al. Effects of intra-articular administration of sodium hyaluronate on plasminogen activator system in temporomandibular joints with osteoarthritis. Oral Surg Oral Med Oral Pathol Oral Radiol Endod. 2010;109(4):541-547. doi:10.1016/j.tripleo.2009.11.007

14. Bjørnland T, Gjaerum AA, Møystad A. Osteoarthritis of the temporomandibular joint: An evaluation of the effects and complications of corticosteroid injection compared with injection with sodium hyaluronate. J Oral Rehabil. 2007;34(8):583-589. doi:10.1111/ j.1365-2842.2007.01759.x

15. Kopp S, Wenneberg B, Haraldson T, Carlsson GE. The short-term effect of intra-articular injections of sodium hyaluronate and corticosteroid on temporomandibular joint pain and dysfunction. J Oral Maxillofac Surg. 1985;43(6):429-435. doi:10.1016/s0278-2391(85)80050-1

16. Møystad A, Mork-Knutsen BB, Bjørnland T. Injection of sodium hyaluronate compared to a corticosteroid in the treatment of patients with temporomandibular joint osteoarthritis: A CT evaluation. Oral Surg Oral Med Oral Pathol Oral Radiol Endod. 2008;105(2):e53-e60. doi:10.1016/j.tripleo.2007.08.024

17. Triantaffilidou K, Venetis G, Bika O. Efficacy of hyaluronic acid injections in patients with osteoarthritis of the temporomandibular joint. A comparative study. J Craniofac Surg. 2013;24(6):2006-2009. doi:10.1097/SCS.0b013e3182a30566

18. Guarda-Nardini L, Tito R, Staffieri A, Beltrame A. Treatment of patients with arthrosis of the temporomandibular joint by infiltration of sodium hyaluronate: A preliminary study. Eur Arch Otorhinolaryngol. 2002;259(5):279-284. doi:10.1007/s00405-002-0456-z

19. Campo GM, Avenoso A, Nastasi G, et al. Hyaluronan reduces inflammation in experimental arthritis by modulating TLR-2 and TLR-4 cartilage expression. Biochim Biophys Acta. 2011;1812(9):1170-1181. doi:10.1016/j.bbadis.2011.06.006 
20. Neo H, Ishimaru Jl, Kurita K, Goss AN. The effect of hyaluronic acid on experimental temporomandibular joint osteoarthrosis in the sheep. J Oral Maxillofac Surg. 1997;55(10):1114-1119. doi:10.1016/ s0278-2391(97)90293-7

21. Shimizu M, Higuchi H, Takagishi K, Shinozaki T, Kobayashi T. Clinical and biochemical characteristics after intra-articular injection for the treatment of osteoarthritis of the knee: Prospective randomized study of sodium hyaluronate and corticosteroid. J Orthop Sci. 2010;15(1):51-56. doi:10.1007/s00776-009-1421-0

22. Dugrillon A, Eichler H, Kern S, Klüter H. Autologous concentrated platelet-rich plasma (CPRP) for local application in bone regeneration. Int J Oral Maxillofac Surg. 2002;31(6):615-619. doi:10.1054/ijom.2002.0322

23. Marx RE. Platelet-rich plasma: Evidence to support its use. J Oral Maxillofac Surg. 2004;62(4):489-496. doi:10.1016/j.joms.2003.12.003

24. De Vos RJ, Weir A, van Schie HTM, et al. Platelet-rich plasma injection for chronic Achilles tendinopathy: A randomized controlled trial. JAMA. 2010;303(2):144-149. doi:10.1001/jama.2009.1986

25. Man D, Plosker H, Winland-Brown JE. The use of autologous platelet-rich plasma (platelet gel) and autologous platelet-poor plasma (fibrin glue) in cosmetic surgery. Plast Reconstr Surg. 2001;107(1):229-237; discussion 238-239. doi:10.1097/00006534200101000-00037

26. Anitua E, Andia I, Ardanza B, Nurden P, Nurden AT. Autologous platelets as a source of proteins for healing and tissue regeneration. Thromb Haemost. 2004;91(1):4-15. doi:10.1160/TH03-07-0440

27. Kiliç SC, Güngörmüş $M$, Sümbüllü $M A$. Is arthrocentesis plus plateletrich plasma superior to arthrocentesis alone in the treatment of temporomandibular joint osteoarthritis? A randomized clinical trial. J Oral Maxillofac Surg. 2015;73(8):1473-1483. doi:10.1016/j. joms.2015.02.026

28. Hegab AF, Ali HE, Elmasry M, Khallaf MG. Platelet-rich plasma injection as an effective treatment for temporomandibular joint osteoarthritis. J Oral Maxillofac Surg. 2015;73(9):1706-1713. doi:10.1016/j. joms.2015.03.045

29. Lana JFSD, Weglein A, Sampson SE, et al. Randomized controlled trial comparing hyaluronic acid, platelet-rich plasma and the combination of both in the treatment of mild and moderate osteoarthritis of the knee. J Stem Cells Regen Med. 2016;12(2):69-78. doi:10.46582/jsrm.1202011

30. Barać B, Damjanov N, Zekovic A. The new treatment approach in knee osteoarthritis: Efficacy of cellular matrix combination of platelet rich plasma with hyaluronic acid versus two different types of hyaluronic acid (HA). Int J Clin Rheumatol. 2019;13(5):289-295. doi:10.4172/1758-4272.1000200

31. Renevier JL, Marc JF, Adam P, Sans N, Le Coz J, Prothoy I. "Cellular matrix ${ }^{\mathrm{TM}}$ PRP-HA": A new treatment option with platelet-rich plasma and hyaluronic acid for patients with osteoarthritis having had an unsatisfactory clinical response to hyaluronic acid alone: Results of a pilot, multicenter French study with long-term follow-up. Int J Clin Rheumatol. 2018;13(4):226-229. doi:10.4172/1758-4272.1000191

32. Wilkes $\mathrm{CH}$. Internal derangements of the temporomandibular joint. Pathological variations. Arch Otolaryngol Head Neck Surg. 1989;115(4):469-477. doi:10.1001/archotol.1989.01860280067019

33. McCain JP, Sanders B, Koslin MG, Quinn JH, Peters PB, Indresano AT. Temporomandibular joint arthroscopy: A 6-year multicenter retrospective study of 4,831 joints. J Oral Maxillofac Surg. 1992;50(9):926-930. doi:10.1016/0278-2391(92)90047-4

34. Sabarish R, Lavu V, Rao SR. A comparison of platelet count and enrichment percentages in the platelet rich plasma (PRP) obtained following preparation by three different methods. J Clin Diag Res. 2015;9(2):ZC10-ZC12. doi:10.7860/JCDR/2015/11011.5536 